\title{
AICD Overexpression in Neuro 2A Cells Regulates Expression of PTCH1 and TRPC5
}

\author{
Mithu Raychaudhuri and Debashis Mukhopadhyay \\ Structural Genomics Section, Saha Institute of Nuclear Physics, 1/AF Bidhan Nagar, WB, Kolkata 700 064, India \\ Correspondence should be addressed to Debashis Mukhopadhyay, debashis.mukhopadhyay@saha.ac.in
}

Received 2 July 2010; Accepted 26 July 2010

Academic Editor: Christiane Reitz

Copyright (C) 2011 M. Raychaudhuri and D. Mukhopadhyay. This is an open access article distributed under the Creative Commons Attribution License, which permits unrestricted use, distribution, and reproduction in any medium, provided the original work is properly cited.

\begin{abstract}
Amyloid precursor protein (APP), implicated in Alzheimer's disease, is a transmembrane protein of undetermined function. APP is cleaved by gamma-secretase that releases the APP intracellular domain (AICD) in the cytoplasm. In vitro and in vivo studies have implicated the role of AICD in cell signaling and transcriptional regulation of Gsk3 $\beta$, KAI1, BACE1, EGFR, and other proteins. In this study, by overexpressing AICD in mouse neuroblastoma cell lines, we have demonstrated the alteration in the expressions of two proteins, patched homolog 1 (PTCH1), a receptor for sonic hedgehog signaling, and transient receptor potential cation channel subfamily C member 5 (TRPC5), a component of receptor-activated nonselective calcium permeant cation channel. Our results indicate the possibility of regulation by AICD in developmental processes as well as in the maintenance of calcium homeostasis at the transcription level.
\end{abstract}

\section{Introduction}

Alzheimer's disease (AD) is an irreversible, progressive neurodegenerative disorder that occurs gradually and results in memory loss, unusual behavior, personality changes, and a decline in thinking abilities. A fundamental abnormality that plays a pivotal role in the dysfunction and death of neurons in $\mathrm{AD}$ is altered proteolytic cleavage of APP. The function of the APP holoprotein is not yet established and mice lacking the APP gene show relatively minor neurological impairments. This subtle phenotype is probably due to compensatory effects mediated by two other members of the APP gene family: amyloid-precursor-like protein-1 and -2 (APLP1 and APLP2). This view is supported by evidence showing that the combined ablation of APP and APLP2, both APLP genes or all three family members together leads to early postnatal lethality [1]. Both the amyloidogenic and nonamyloidogenic pathways, that is, the cleavages of APP by $\beta$ - and $\alpha$-secretases, respectively, liberate the soluble ectodomain of APP (ectodomain shedding) and retain the C-terminal fragments (CTF) (CT99 and CT83, resp.). Subsequent cleavages by $\gamma$-secretase in the transmembrane domain generate the amyloidogenic $\mathrm{A} \beta$ peptide or the nonamyloidogenic $\mathrm{p} 3$ peptide along with the intracellular C-terminal domain of APP (AICD). Biochemical and genetic interaction screens have led to the identification of both extracellular and multiple intracellular binding partners, which seem to anchor the APP/APLP C-termini to a complex protein network at the cell surface, which may transduce various cellular responses [2, 3]. Notably, a highly conserved cytoplasmic${ }^{682}$ YENPTY $^{687}$ - motif is present in all APP/APLP family members, which confers clathrin-mediated endocytosis and was shown to bind several multidomain adaptor proteins, including X11/Mints, Fe65 family proteins and mDab [4]. A number of type-I transmembrane proteins including Notch, p75NTR, CD44, ErbB4, neuregulin-1, and alcadein undergo a similar secretase mediated processing leading to ectodomain shedding and generation of intracellular domains (ICD's) [5]. Some of these ICD's are known to take part in cellular differentiation and development by nuclear signaling and transcriptional transactivation [6]. Like NICD (Notch intracellular domain), several recent studies have suggested that AICD has transactivation activity and can regulate transcription of multiple genes including APP, GSK- $3 \beta$, 
TABle 1: Primer sequences and PCR conditions of real-time PCR.

\begin{tabular}{|c|c|c|c|c|}
\hline Name of the genes & PCR condition & PCR Cycle & Primer sequences $\left(5^{\prime}-3^{\prime}\right)$ & Size (bp) \\
\hline \multirow[t]{2}{*}{ PTCHI } & $\begin{array}{l}95^{\circ} \mathrm{C} \rightarrow 10 \mathrm{~min} \\
{\left[95^{\circ} \mathrm{C} 30 \mathrm{sec}, 50^{\circ} \mathrm{C}\right.} \\
\left.30 \mathrm{sec}, 60^{\circ} \mathrm{C} 1 \mathrm{~min}\right]\end{array}$ & \multirow[t]{2}{*}{35} & \multirow[t]{2}{*}{$\begin{array}{l}\text { GAAAAATGAGCAGAACCATGG } \\
\text { TGTCTTCCTTCTGAACCCCTG }\end{array}$} & \multirow[t]{2}{*}{102} \\
\hline & $72^{\circ} \mathrm{C} \rightarrow 10 \mathrm{~min}$ & & & \\
\hline \multirow[t]{2}{*}{ TRPC5 } & $\begin{array}{l}95^{\circ} \mathrm{C} \rightarrow 10 \mathrm{~min} \\
{\left[95^{\circ} \mathrm{C} 30 \mathrm{sec}, 50^{\circ} \mathrm{C}\right.} \\
\left.30 \mathrm{sec}, 60^{\circ} \mathrm{C} 1 \mathrm{~min}\right]\end{array}$ & \multirow[t]{2}{*}{35} & \multirow[t]{2}{*}{$\begin{array}{l}\text { TTCCAGCTCTCTTCACTGTGC } \\
\text { AAGTCACAAGCCTCTCCCCAA }\end{array}$} & \multirow[t]{2}{*}{102} \\
\hline & $72^{\circ} \mathrm{C} \rightarrow 10 \mathrm{~min}$ & & & \\
\hline \multirow[t]{2}{*}{ Beta actin } & $\begin{array}{l}95^{\circ} \mathrm{C} \rightarrow 10 \mathrm{~min} \\
{\left[95^{\circ} \mathrm{C} 30 \mathrm{sec}, 55^{\circ} \mathrm{C}\right.} \\
\left.30 \mathrm{sec}, 60^{\circ} \mathrm{C} 1 \mathrm{~min}\right]\end{array}$ & \multirow[t]{2}{*}{35} & \multirow[t]{2}{*}{$\begin{array}{l}\text { TCCTGTGGCATCCACGAAACT } \\
\text { GAAGCATTTGCGGTGGACGAT }\end{array}$} & \multirow[t]{2}{*}{315} \\
\hline & $72^{\circ} \mathrm{C} \rightarrow 10 \mathrm{~min}$ & & & \\
\hline
\end{tabular}

KAI1, neprilysin, BACE, and EGFR [7-11]. Recently, it has been shown that AICD-mediated transcriptional regulation of EGFR by directly binding to the EGFR promoter [11].

The role of APP in neuronal development and in calcium homeostasis is well established $[1,12,13]$. The expression of APP in brain is developmentally regulated and it is expressed ubiquitously in differentiated neurons. APP is axonally transported and secreted forms of APP (sAPPs) are released from neurons in an activity-driven manner. Secreted APPs modulate neuronal excitability, counteract effects of glutamate on growth cone behaviors, and increase synaptic complexity [14]. Moreover, aberrant processing of APP can also cause neurodegeneration by impairing a neuroprotective function sAPPs which normally regulate calcium homeostasis $[12,15]$.

But the role of AICD, if any, in both developmental processes and in maintenance of calcium ion homeostasis is yet to be elucidated. In the present study, we intended to look into the possibility of AICD having any role in the transcriptional regulation of the components of sonic hedgehog pathway and calcium channel forming proteins. Initially, microarray analysis was done to screen the genes whose expression would alter upon AICD overexpression (data not shown).

\section{Materials and Methods}

2.1. Cloning of AICD in pGFP C1 Vector. For the overexpression of AICD in mammalian cell line, it was cloned in pGFP vector. Specific primers for AICD (Forward: 5' ACGCGTCGACAAGAAGAAACAGTACACATCC3' and the Reverse: 5'CGGGATCCTAGTTCTGCATCTGCTCAAAGAA $\mathrm{C}^{\prime}$ ) with adaptors (underlined), for the restriction enzymes (RE) SalI and BamH1, were synthesized (Integrated DNA Technologies) to amplify the domain using brain c-DNA library (Stratagen) as template. PCR products were digested with SalI and BamH1 (New England Biolabs) and ligated to pGFP C1 vector (BD Biosciences). Construct was confirmed both by DNA sequencing and restriction enzyme digestion.
2.2. Cell Culture and Transfection. Neuro 2A cells were obtained from National Cell Science Centre, Pune, India and were cultured in DMEM (HiMedia) supplemented with $10 \%$ fetal bovine serum (Invitrogen) at $37^{\circ} \mathrm{C}$ in $5 \% \mathrm{CO}_{2}$ atmosphere under humidified condition. Transfection of cells with empty vector (pGFP C1) or AICD-GFP was performed using Lipofectamine 2000 Transfection Reagent (Invitrogen).

2.3. Protein Extraction. For extraction of proteins, PBSwashed pellets from cell lines were lysed on ice in lysis buffer (50 mM Tris- $\mathrm{HCl}, \mathrm{pH} 7.5,150 \mathrm{mM} \mathrm{NaCl}, 15 \mathrm{mM}$ EDTA, $0.5 \%$ Triton $\mathrm{X}-100$ ) for $30 \mathrm{~min}$ in presence of Complete protease inhibitor (Roche Diagnostics) and centrifuged at 13,000 rpm for 15 minutes. Protein concentration was determined by Bradford protein estimation assay.

2.4. RNA Isolation, c-DNA Preparation and Real-Time PCR. RNA was isolated from Neuro 2A cells by RNeasy Mini Kit (Qiagen, Hilden, Germany) following the manufacturers protocol. RNA equivalent to $500 \mathrm{ng}-1 \mu \mathrm{g}$ was taken to synthesize the first strand cDNA using random hexamer primers and reverse transcriptase (Invitrogen). Real time RT-PCR reaction was carried out using Syber green $2 \mathrm{X}$ Universal PCR Master Mix (Applied Biosystems, USA) in ABI Prism 7500 sequence detection system. Each reaction was performed in triplicate using $100 \mathrm{ng}$ of total RNA using corresponding primer sequences (primer sequences and PCR conditions were mentioned in the Table 1). For each gene, nontemplate control was used at the same condition to ascertain the baseline and threshold value for the analysis. The absolute quantification given by the software was in terms of Ct values. The relative quantification of a target gene in a sample compared to parental cell is expressed in terms of $2^{-\Delta \Delta \mathrm{Ct}}$ values after normalization with respect to internal control ( $\beta$-actin gene).

2.5. Western Blot. Proteins were separated on SDSpolyacrylamide gels and transferred onto PVDF membranes 


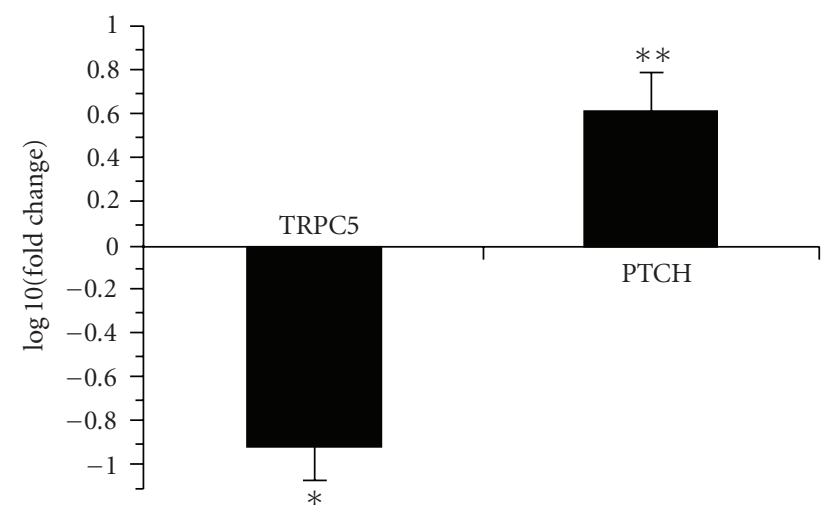

(a)

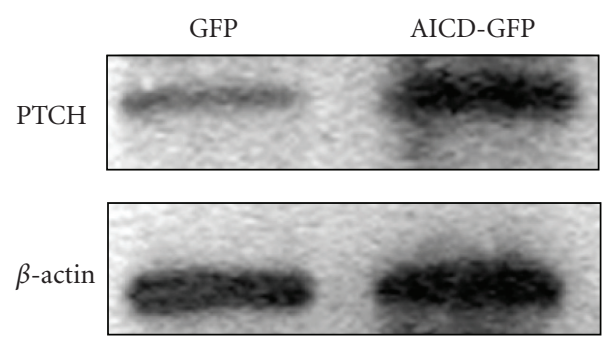

(i)

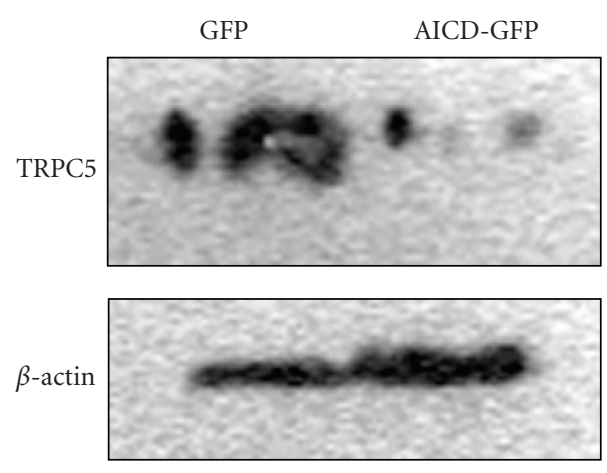

(iii)

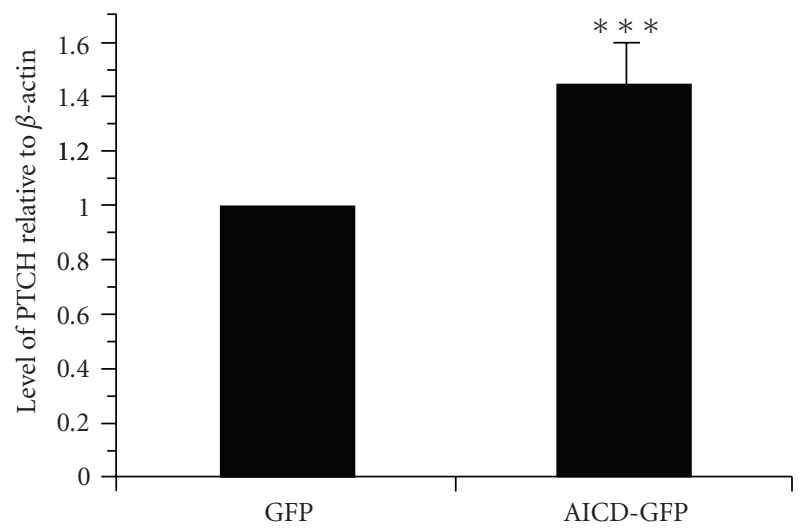

(ii)

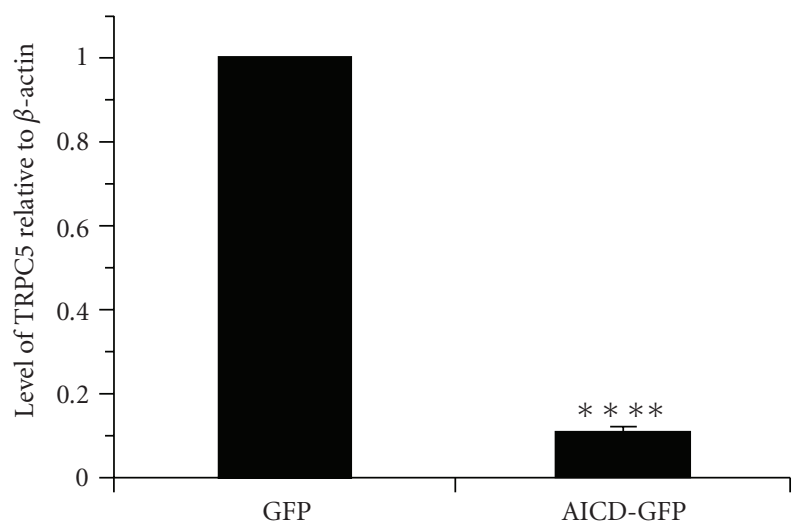

(iv)

(b)

FIGURE 1: (a) RNA was isolated from Neuro 2A cells transfected with either GFP or AICD-GFP. The first strand cDNA was synthesized using random hexamer primers and reverse transcriptase. Using that c-DNA as template, expression of PTCH1 and TRPC5 were also checked by real-time PCR in both the cell lines. The relative quantification of both the genes in AICD-GFP transfected cell compared to only GFP transfected cell were expressed in terms of $2^{-\Delta \Delta \mathrm{Ct}}$ values after normalization with respect to internal control (beta-actin gene) and plotted in $\log$ scale $(\log 10$ (Fold change) $) *$ indicated $P<.02$ and $* *$ indicated $P<.05$. (b) Proteins were prepared from both GFP and AICD-GFP transfected cells after 24 hours of transfection, run on SDS-PAGE and western blot was done with antibody against PTCH1 (i) as well as TRPC5 (iii) and beta actin as loading control in both the cases. Fold change was calculated by densitometry analysis taking beta-actin as loading control (ii) and (iv). ${ }^{* * *}$ indicated $P<.05$ and $* * * *$ indicated $P<.005$. 
(Millipore Corporation), which were blocked by incubation in 5\% dried milk in TBST (50 mM Tris- $\mathrm{HCl}, 150 \mathrm{mM} \mathrm{NaCl}$, pH 7.5 containing $0.05 \%$ Tween 20). Membranes were probed with primary antibodies against PTCH (ab53715, Abcam plc, 1 : 1000); TRPC5 (ab58374, Abcam plc, $1 \mu \mathrm{g} / \mathrm{mL}$ ); beta actin (loading control for whole cell extracts; Abcam plc, 1:5000). HRP-conjugated antibodies (Chemicon; 1:5000) were then added to the blots. Immunoreactive bands were detected with enhanced chemiluminescence reagent (Super Signal West Pico Substrate; Pierce) and signals were visualized by exposing the membranes to ECL Hyperfilm (Amersham Biosciences). Quantification of western blots was carried out using Quantity One software of Bio-Rad. At least three separate experiments were analyzed and band intensities were normalized to loading control. $P$-values were determined using unpaired $t$-tests.

Mean and standard deviation were calculated by Microsoft Office Excel 2007. The error bar represents standard error $(($ standard deviation $/ \sqrt{ } n) n=$ sample size $)$.

\section{Results and Discussion}

From microarray experiment we got the hint that AICD overexpression might alter the expression level of PTCH1 and TRPC5 (data not shown). To provide further evidence, the mRNA expression levels of both the proteins were checked by real-time PCR using total RNA from AICDGFP overexpressed cells and compared those with the expression of only pGFP C1 transfected cells. About 2fold increase and 3-fold decrease in the expressions of PTCH1 and TRPC5, respectively, was observed upon AICD overexpression (Figure 1(a)). The changes in the expressions of the genes at RNA level was further verified at protein levels also. By western blot analysis it was revealed that endogenous PTCH1 level was raised 1.5 fold (Figure 1(b), panels (i) and (ii)) and TRPC5 level was decreased 9 fold (Figure 1(b), panels (iii) and (iv)) in AICD-GFP overexpressing Neuro 2A cells compared to control.

PTCH1 acts as a receptor for sonic hedgehog $(\mathrm{SHH})$ [16] and seem to have a tumor suppressor function, as inactivation of this protein is probably a necessary, if not sufficient step for tumorigenesis [17]. Defects in PTCH1 are known to be a cause of sporadic basal cell carcinoma (BCC) [18]. Hence overexpression of PTCH1 by AICD could be a protective measure of cells against tumorigenesis. This observation seems to be interesting because AICD is previously reported to modulate EGFR-mediated tumorigenesis by reducing the expression of EGFR [11].

On the other hand TRPC5 forms a receptor-activated nonselective calcium permeant cation channel. TRPC1 and TRPC5 are subunits of a heteromeric neuronal channel in mammalian brain [19]. TRPC5 is reported to colocalize with stathmin-like-2, a neuronal growth protein, within the vesicles and in the growth cone. A dominant-negative form of TRPC5 allowed significantly longer neurites and filopodia to form, suggesting that TRPC5 regulates neuronal growth [20]. It was also reported that influxes of calcium via voltage-gated channels play a role in neuronal outgrowth and suggested that TRPC5 is a candidate for the regulation of calcium waves [20]. A decrease in the expression of TRPC5 by AICD overexpression might affect neurite outgrowth.

\section{Conclusion}

In conclusion, our results suggest that overexpression of AICD can modulate both developmental and degenerative pathways in the cell. Whether the cell would take the survival or the degenerative route at the end depends on other regulatory parameters.

\section{Acknowledgment}

This work was supported by the SPGHGD (DAE) project, Government of India.

\section{References}

[1] S. Heber, J. Herms, V. Gajic et al., "Mice with combined gene knock-outs reveal essential and partially redundant functions of amyloid precursor protein family members," Journal of Neuroscience, vol. 20, no. 21, pp. 7951-7963, 2000.

[2] B. De Strooper and W. Annaert, "Proteolytic processing and cell biological functions of the amyloid precursor protein," Journal of Cell Science, vol. 113, no. 11, pp. 1857-1870, 2000.

[3] E. H. Koo, "The beta-amyloid precursor protein (APP) and Alzheimer's disease: does the tail wag the dog?" Traffic, vol. 3, pp. 763-770, 2002.

[4] M. Raychaudhuri and D. Mukhopadhyay, "AICD and its adaptors-in search of new players," Journal of Alzheimer's Disease, vol. 11, no. 3, pp. 343-358, 2007.

[5] K. Heese and H. Akatsu, "Alzheimer's disease - an interactive perspective," Current Alzheimer Research, vol. 3, no. 2, pp. 109121,2006

[6] S. P. Sardi, J. Murtie, S. Koirala, B. A. Patten, and G. Corfas, "Presenilin-dependent ErbB4 nuclear signaling regulates the timing of astrogenesis in the developing brain," Cell, vol. 127, no. 1, pp. 185-197, 2006

[7] X. Cao and T. C. Sudhof, " transcriptionally [correction of transcriptively] active complex of APP with Fe65 and histone acetyltransferase Tip60," Science, vol. 293, no. 5534, pp. 115120, 2001.

[8] R. Pardossi-Piquard, A. Petit, T. Kawarai, et al., "Presenilindependent transcriptional control of the Abeta-degrading enzyme neprilysin by intracellular domains of betaAPP and APLP," Neuron, vol. 46, pp. 541-554, 2005.

[9] R. C. von Rotz, B. M. Kohli, J. Bosset et al., "The APP intracellular domain forms nuclear multiprotein complexes and regulates the transcription of its own precursor," Journal of Cell Science, vol. 117, no. 19, pp. 4435-4448, 2004.

[10] H. S. Kim, E. M. Kim, J. P. Lee, et al., "C-terminal fragments of amyloid precursor protein exert neurotoxicity by inducing glycogen synthase kinase-3beta expression," The FASEB Journal, vol. 17, pp. 1951-1953, 2003.

[11] Y.-W. Zhang, R. Wang, Q. Liu, H. Zhang, F.-F. Liao, and $\mathrm{H}$. $\mathrm{Xu}$, "Presenilin $/ \gamma$-secretase-dependent processing of $\beta$ amyloid precursor protein regulates EGF receptor expression," Proceedings of the National Academy of Sciences of the United States of America, vol. 104, no. 25, pp. 10613-10618, 2007.

[12] S. W. Barger, V. L. Smith-Swintosky, R. E. Rydel, and M. P. Mattson, " $\beta$-Amyloid precursor protein mismetabolism and 
loss of calcium homeostasis in Alzheimer's disease," Annals of the New York Academy of Sciences, vol. 695, pp. 158-164, 1993.

[13] Y. Chen and B. L. Tang, "The amyloid precursor protein and postnatal neurogenesis/neuroregeneration," Biochemical and Biophysical Research Communications, vol. 341, no. 1, pp. 15, 2006.

[14] M. P. Mattson and K. Furukawa, "Signaling events regulating the neurodevelopmental triad glutamate and secreted forms of $\beta$-amyloid precursor protein as examples," Perspectives on Developmental Neurobiology, vol. 5, no. 4, pp. 337-352, 1998.

[15] M. P. Mattson, R. E. Rydel, I. Lieberburg, and V. L. SmithSwintosky, "Altered calcium signaling and neuronal injury: stroke and Alzheimer's disease as examples," Annals of the New York Academy of Sciences, vol. 679, pp. 1-21, 1993.

[16] E. H. Villavicencio, D. O. Walterhouse, and P. M. Iannaccone, "The sonic hedgehog-patched-gli pathway in human development and disease," American Journal of Human Genetics, vol. 67, no. 5, pp. 1047-1054, 2000.

[17] D. M. Stone, M. Hynes, M. Armanini et al., "The tumoursuppressor gene patched encodes a candidate receptor for sonic hedgehog," Nature, vol. 384, no. 6605, pp. 129-134, 1996.

[18] H. Hahn, C. Wicking, P. G. Zaphiropoulos et al., "Mutations of the human homolog of drosophila patched in the nevoid basal cell carcinoma syndrome," Cell, vol. 85, no. 6, pp. 841851, 1996.

[19] C. Strübing, G. Krapivinsky, L. Krapivinsky, and D. E. Clapham, "TRPC1 and TRPC5 form a novel cation channel in mammalian brain," Neuron, vol. 29, no. 3, pp. 645-655, 2001.

[20] A. Greka, B. Navarro, E. Oancea, A. Duggan, and D. E. Clapham, "TRPC5 is a regulator of hippocampal neurite length and growth cone morphology," Nature Neuroscience, vol. 6, no. 8, pp. 837-845, 2003. 


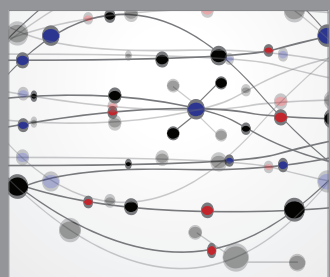

The Scientific World Journal
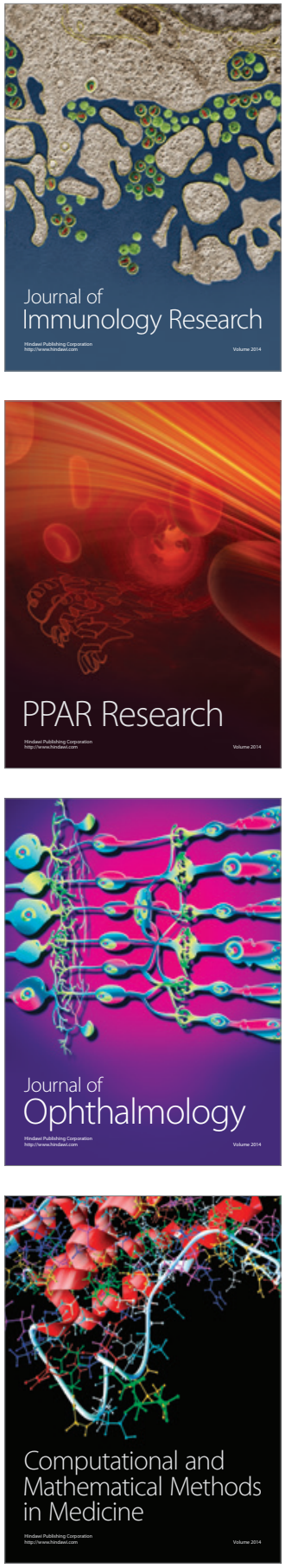

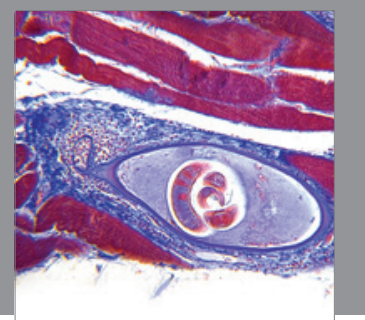

Gastroenterology

Research and Practice
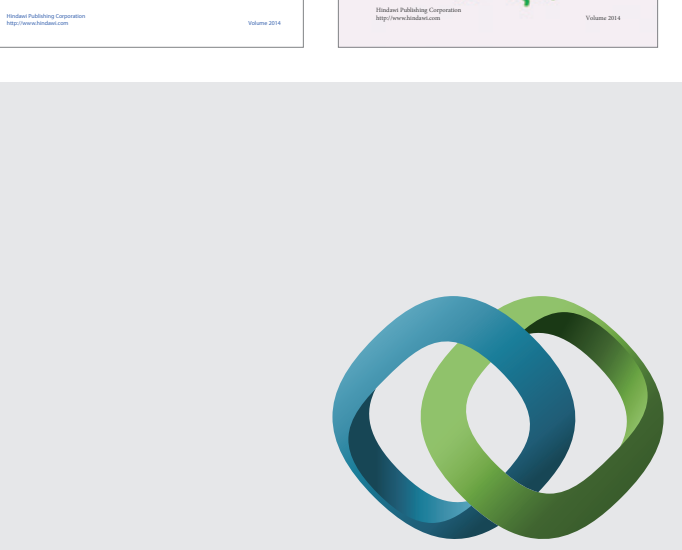

\section{Hindawi}

Submit your manuscripts at

http://www.hindawi.com
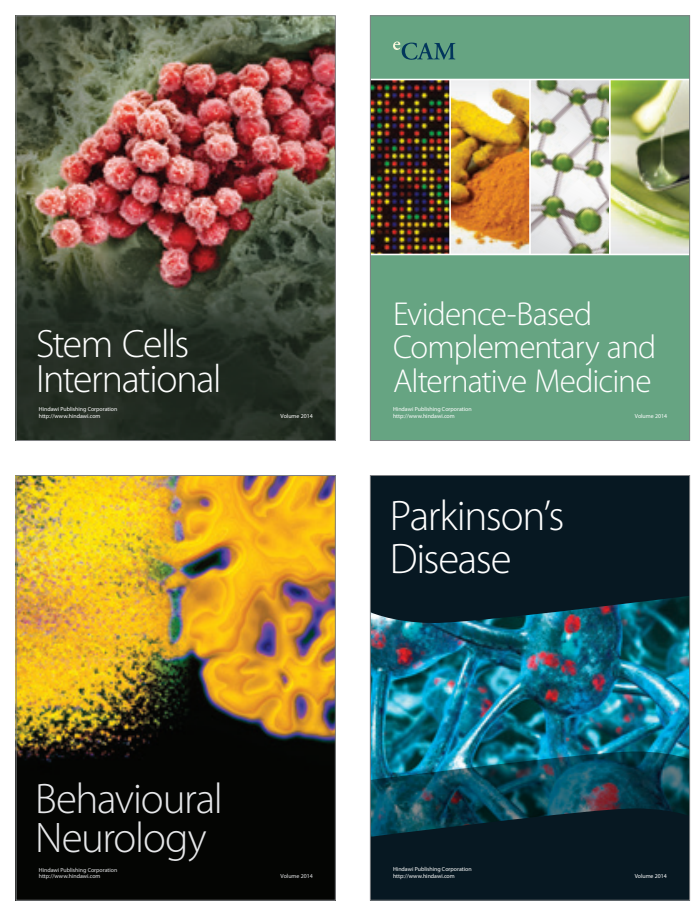

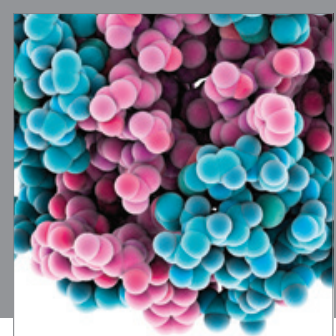

Journal of
Diabetes Research

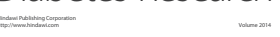

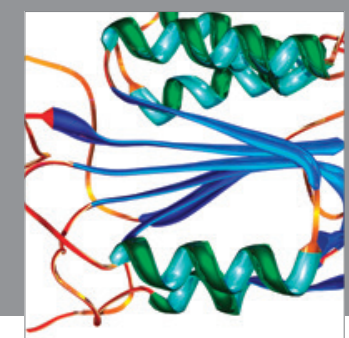

Disease Markers
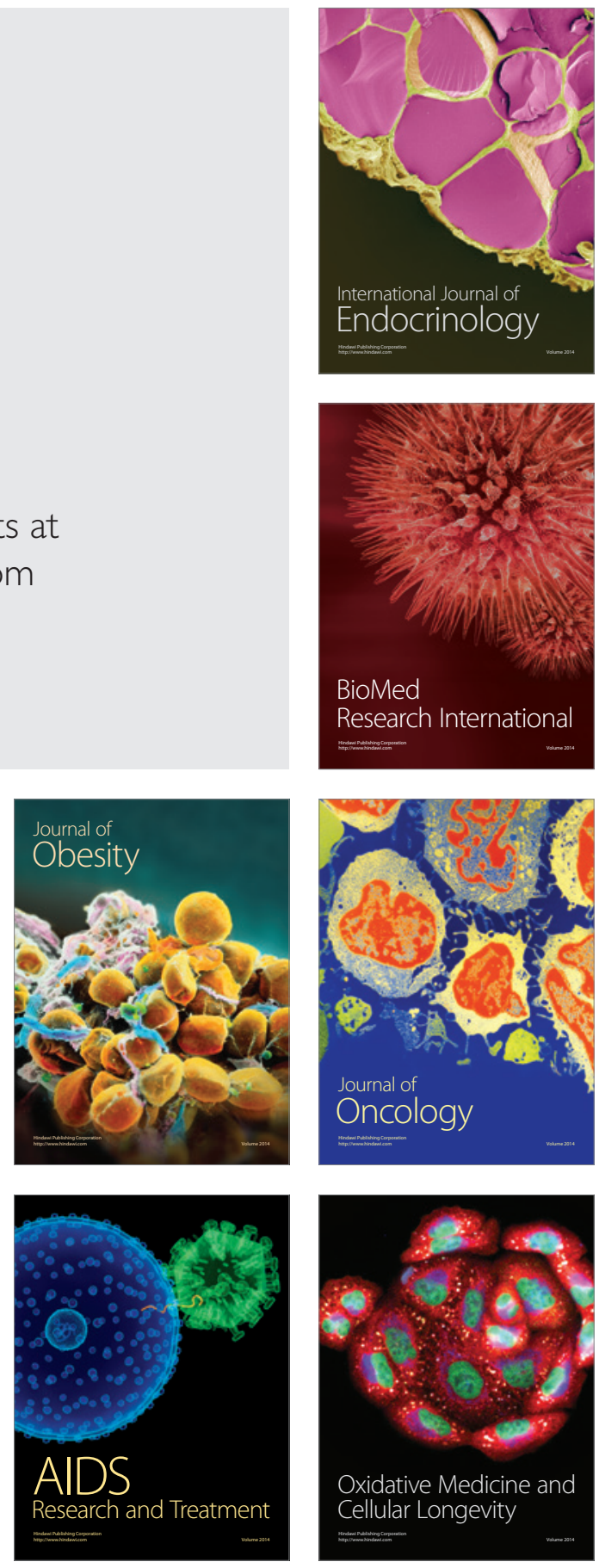